\title{
Discussion on the Establishment of Transfer Board System in China's New Three Board: A Case Study
}

\author{
Ling Sun \\ School of Management, Wuhan University of Technology, Wuhan, P.R.China, 430070
}

2264343941@qq.com

Keywords: Transfer plate system; New three board; Econtrol

\begin{abstract}
With the increasing number of new three board enterprises, the transfer board system has become a hotspot. Based on the theory of corporate finance growth cycle, this paper constructs the analysis framework of the demand for the transition of enterprises in the growth period, and takes the case of Econtrol transferring board to the GEM as as the research object. Through the analysis of the motives, conditions and cost ,the paper analyzes the necessity of establishing the system of on-the-spot market in the field from the aspect of enterprise, and puts forward some suggestions on how to establish the new three board transferring board system.
\end{abstract}

\section{Research Background}

Since its inception in 2006, the number of new three board companies has been increasing, especially after the 2013 expansion. In the case of rapid expansion, the new three board has not yet established a formal rotation board system ,as "incubator" and "reservoir" of a listed company. As early as December 2013, the State Council has proposed to establish links between the different levels of the market. It provides the company listed in the national share transfer system can directly apply to the stock exchange after meetting the requirements of stock listing. But until now there is no clear implementation rules. Which also led to such as Xiangcai Securities registered capital of 3.5 billion in large companies are listed on the OTC market. There are not many foreign literatures on the transfer mechanism. After hundreds of years of development, stock market in the western developed countries, already has been mature, with a relatively sound and perfect mechanism to the transfer plate, the existing literature of which mainly focuses on the market reaction after the listed company transferring. In the domestic research, scholars generally believe that the transfer system will help multi-level capital market to become an organic whole, contribute to the adjustment of industrial structure, improve the optimal allocation of social resources, and most of scholars are willing to explore a suitable way for transferring mechanism for the development of China's capital market by the comparing transfer mechanism of western countries. However, there is little literature from the case study method, using the theory of case verification. This paper, choosing econtrolas the case ,who loged on to the gem through the IPO, listing the three-board originally, analyses its listing motives, conditions, cost, and explains the importance to establish a sound transfer system for the new three board. Also it will provide some suggestions about the construction of China's multi-level capital market.

\section{Framework of the Case Analysis}

There are two theoretical supports in the aspect of the support of the mechanism of the transfer mechanism, namely, the theory of enterprise financial growth cycle and the theory of signal transmission. Weston puts forward the theory of corporate finance growth cycle, which divides the enterprise life into three different stages: early, mature and recession. And Berger thinks that the transparency of information, the scale of enterprises and the financing demand are the main factors that affect the financing structure of small businesses in the United States, based on the theory of information economics. So, the need of enterprises for financing will be corresponded as it continues to grow ,as well as its financing channels, with the improvement of the transparency of information and the expanding of its size. However, there wil be a best financing scale matched 
with each growth cycle stage. In the growth stage of the enterprise, the high growth is accompanied by the high operating risk, the best way of financing should be the equity financing rather than the debt financing. Listing is preferred. Under the system of capital market in China, there are not only complicated procedures, long waiting period, but also high cost. Some companies may seek a second choice in the new board listed financing, which can solve some of the financing needs .But enterprises will inevitably seek other equity financing channels after a certain period of time in the new board ,since its lacking of liquidity. Then listing became the only choice. When enterprises reach the basic requirement of going public, they will turn to the way from the new three board to the GEM. For there is no connection between the new three board and the GEM in multi-level capital market in China, they can only go public through IPO instead of "green channel", which may bring higher costs.

\section{Motivation Analysis}

Econtrol was established in 1997, the first domestic RTU products. In 2008, Econtrol successfully listed on the new board. Along with the automation construction across the country oil field continues to accelerate, RTU products are favored by the oil customers. Econtrol's business scale and profitability rapidly expand The main motive for Econtrol to list is financing. Its financing needs are mainly affected by the scale of operation and the characteristics of the products. In about 5 years time, Econtro has been rapid development, but in financing needs, especially the new three board financing services to provide, more stretched. The following from the scale of operation and product structure analysis of security financing needs.

Changes of Business Scale. After years of efforts, Econtrol has developed into a complete industrial chain with RTU enterprises. In the concept of continuous innovation, the company's products and services have been upgraded to expand the domestic market share. Since listing in the new three board in August 20, 2008,Econtrol continues to expand the scale of its business ,as shown in Fig. 2.From the growth cycle point of view, Econtrol is in the transition period from the start to the growth stage. With the rapid development of business and business scale rapid expansion, Econtrol needs to get more financial support. After the listing of the new three boards, Econtrol has more financing channels than before, especially bank credit. Econtrol short-term loan balance is growing.

Table 1 Changes in short-term borrowing [million]

\begin{tabular}{|l|l|l|l|l|l|l|}
\hline Year & Order & Credit & Mortgage & Pledged & Guaranteed & Balances \\
\hline 2007 & & & 400 & & 400 & 800 \\
\hline 2008 & & & & & 1000 & 1000 \\
\hline 2009 & & & & & 1500 & 1600 \\
\hline 2010 & 350 & 500 & & & 1500 & 2350 \\
\hline 2011 & & & & 600 & 9500 & 10100 \\
\hline 2012 & & & & & 15200 & 15200 \\
\hline 2013 & & & & & 20300 & 20300 \\
\hline
\end{tabular}

However, Econtrol hasn't finance through private placement in the new three board market so far. With the expansion of the scale of business, though Econtrol has reached the listing standards of gem, it can't transfer plate. Because the transfer mechanism is not perfect. The new three board trading activity is small and its transaction volume is far behind the capital market in other higher level plate. It is difficult to meet the security needs of security control technology. Although the indirect financing provided by banks can meet the demand of short-term funds for Econtrol to a certain extent, the demand of long-term funds is harder to meet.

Product Structure Analysis. The company's products are divided into two blocks, RTU products and overall solutions related to it. The characteristics of its products determine the 
financing needs of Econtrol. Automation technology products are industrial automation products. On the one hand, due to the performance and industry requirements, it takes long time to research and achieve market recognition, so the capital investment is more than other products. On the other hand, it's long life cycle for the product to obtain market recognition. Its product specificity determines its long-term funding needs. In foreign countries, automation products for the market recognition, the life cycle can be maintained at 10 years, or even longer. It takes a long time for Econtrol products from R \& D to the market mature. During this time, the enterprise still need funds to invest in product research and development. But, the general bank credit can not afford such funds, considering the high risk of R \& D.So, the Econtrol only chooses to meet its financing needs in capital markets. However, the new three board transactions are less active, funds supporting by which are difficult to match the development of the Econtrol. that's also the reason why the Econtrol wants to go to the GEM. In summary, the expansion of the scale of the Econtrol leads to its Substantial financing needs. And it is difficult to be resolved by short-term fundingin, as well as in the new three board market. that's all resulting in rotating board motive of the Econtrol.

\section{Conditional Analysis}

At present, the new three board enterprises with the appropriate conditions, can submit to the CSRC to apply for transfer transactions. If the CSRC accept the application, the company can transfer board to the GEM by the way of IPO. For example, companies who want to listed on the GEM enterprises should meet the following three core conditions:

First of all, the main body of the application needs to continuously operate for three years or more, and should be established according to law, and the main business is in line with national industrial policies and related regulations. The Econtrol was established in 1997, the main business is the sales of RTU products, having met the requirements of the GEM. Secondly, the financial should keep sustained positive growth and accumulated no less than 10 million yuan in the last two years. After listing, the total share capital is not less than 30 million, no relevant provisions before the issue. In the new three board in more than 5 years, the net profit of Econtrol continued to achieve positive growth, for example, the first two years the total net profit reached 8,755.39 million, far more than the GEM in the financial requirements. It can be seen that the Econtrol has a strong strength in the aspect of size, operating income and net profit. Although the Econtrol has achieved the requirements of the transfer board after listing in the new three board in three years, it can only choose the SFC approval to go to the GEM through the IPO. This system does not facilitate the new three board listed companies to transfer plate and cost much. This system arrangement, rooted in China's listed issuance of the approval system. Once IPO stagnation, the listing enterprises in new three board will be delayed.

\section{Cost Analysis}

Capital Cost. The Econtrol successfully listed on the GEM in January 23, 2014.In this public offering, The Econtrol issued 13 million shares of public shares publicly, accounting for $27.67 \%$ of the total issued share capital. In the IPO, the total amount of funds raised by The Econtrol is 175 million, the net proceeds of 148 million. The issue costs reached 27 million yuan. The specific cost type is shown in figure 3. We can see from Figure 3, underwriting sponsor costs accounted for $2 / 3$ of the total cost of issuance. In addition, the total issuance costs accounted for $15 \%$ of the cost of funds raised. Although the issue fee is deducted from the total amount of funds raised, for profits of 45 million small and medium enterprises, 270,400 of the issuance fee is not a small number. 


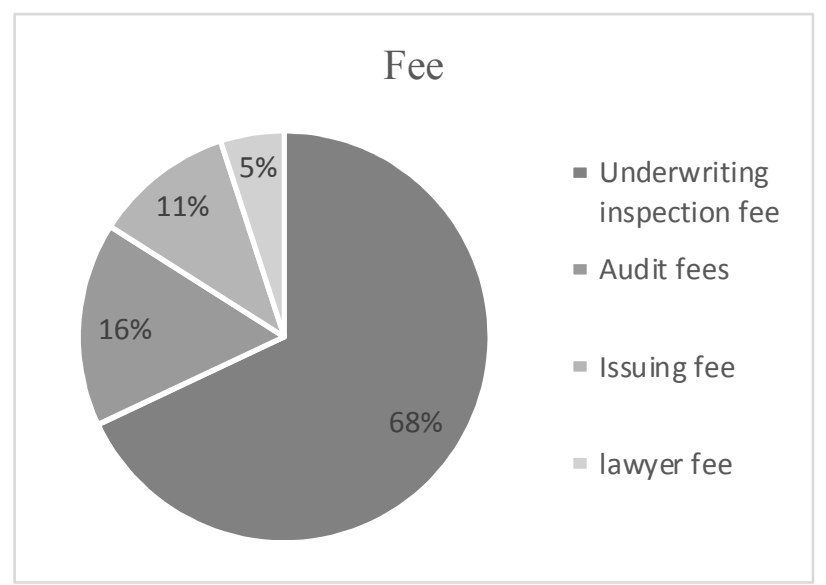

Figure 1. Finite Issue cost of Econtrol

Time Cost. Review of science and technology from the new board to gem, the process is very tortuous. Its process schedule is shown table 2.

Table 2 Issuing process of Econtrol

\begin{tabular}{|l|l|}
\hline Time & Event \\
\hline 2010.12 .08 & The initial public offering is approved by the shareholders \\
\hline 2011.07 .06 & Suspension of the transfer in the new board, waiting for the trial \\
\hline 2012.05 .18 & Successfully passed the audit, waiting for listing \\
\hline 2013.12 .17 & IPO application by the shareholders of the second meeting \\
\hline 2014.01 .06 & Gem issuance for the first time disclosed \\
\hline 2014.01 .09 & Termination of the National SME stock system listing \\
\hline 2014.01 .23 & IPO successful, Landing on the GEM \\
\hline
\end{tabular}

In August 20, 2008, the Econtrol listed in the new three board. After 2 years of listing on the new board, the Econtrol has been developed greatly, so, it considers to list on a higher and more active capital market. In December 2010,the Econtrol began to put forward for the board. But it's not until January 23, 2014 that was listed on the gem. From the application to the final GEM listing, it's up to 3 years .And this is not a case. Century Oriental, Star Hao medicine, Shuangjie electrical and other applications, all encountered a long period of shares suspended transfer.

\section{Conclusions}

Establish Efficient and Convenient Transfer Mechanism. First of all, the new three board construction needs attention. All along, the construction of the third board market is difficult to get the attention of the relevant management. However, the new three board is a good way to solve the problem of financial financing forthe small and medium enterprises. Secondly, it should establish a efficient channe to transfer. Companies having meet the conditions listed are considered to directly go to Shanghai or Shenzhen Stock Exchange. Finally, variety of ways to turn board should be established.

Improve the Supporting System Construction. The liquidity of the capital market is closely related to the enthusiasm of both sides. The liquidity of the capital market, to a certain extent, also affects the attractiveness of the capital market, the development and financing functions. The establishment of a sound mechanism will in turn stimulate the new three board supporting system to improve. First, continue to improve the trading system. Secondly, the introduction of institutional investors. Finally, appropriatly introdue a collection of trust, bank financing, investment funds and other financial assets or product funds, to reduce the threshold of natural person investors into the 
market.

Establish Hierarchical Mechanism Within the Board. To establish a perfect stratification mechanism is of great significance to further optimize the allocation of resources. First, establishing a plate within the layered mechanism. Second, providing convenient transfer board services. Finally, establishing a sound delisting mechanism. It's necessary to strengthen the new three board and the equity trading center throughout the country, to open up the new three board delisting channels, to maintain the new three board this "reservoir" vitality and vitality.

\section{References}

[1] J.S. Zhang: Economic System Reform, Vol. 26 (2012) No.01,p.107.(In Chinese)

[2] A.J. Lin: Economic Reform, Vol. 11 (2012) No.05,p.111.(In Chinese)

[3] C.Y. Tan: Modern Economic Information, Vol. 26 (2014) No.10,p.337.(In Chinese)

[4] N. Liu: Financial, Vol. 26 (2015) No.10,p.79.(In Chinese)

[5] D.Y. Wang: Research on the bidirectional rotation system between China's gem and the new three board (Ph.D., University of International Business and Economics, China 2015),p.28. (In Chinese)

[6] M.X. Chen: Era of Finance, Vol. 27 (2013) No.29,p.25.(In Chinese).

[7] H.P. Guo: Financial Sector, Vol. 33 (2014) No.17,p.149.(In Chinese)

[8] K.D Shih: Journal of Financial Markets, Vol. 17 (2012) No.14,p.109.

[9] E.M. Devos, J.K. Kun and Y.T. Green: Advances in Investment Analysis and Portfolio Management, Vol. 57(2014 ) No.06,p.111.

[10] Information on http://www.stock.hexun.com 